\title{
«Mártires da Liberdade». O exílio de revolucionários espanhóis nos Açores (1866-1868) na perspectiva da imprensa local ${ }^{1}$
}

\author{
Carlos Cordeiro \\ Susana Serpa Silva
}

\section{A SITUAÇÃo POlítico-MILITAR EM ESPANHA NA PERSPECTIVA DA IMPRENSA AÇORIANA}

A complexa situação política que a Espanha viveu na década de sessenta do século XIX teve, naturalmente, grande repercussão em Portugal. As notícias, comentários, transcrições de manifestos, proclamações, comunicados percorriam as páginas dos jornais, deixando bem expressos os respectivos posicionamentos políticos e ideológicos, sobretudo em contextos de tipo golpista ou revolucionário. No fundo, não se deixava de destacar que podia estar em causa a própria independência nacional, como chamava a atenção um jornal de Angra do Heroísmo (ilha Terceira, Açores), em Janeiro de 1866. Aquando do golpe de 2 de Janeiro de 1866 conduzido pelo general Juan Prim, e numa situação em que, como referia o jornal, podia ser ameaçada a «autonomia portuguesa», o governo português tomara as necessárias medidas de protecção na fronteira ${ }^{2}$. Ainda que não o referindo expressamente, o jornal aludia, de forma indirecta, ao debate sobre o iberismo que, periodicamente, num e noutro lado da fronteira, despontava, sobretudo ao nível das questões ideológicas e que depois, e no contexto da Revolução de 1868 em Espanha, ressurgiria com mais premência ${ }^{3}$.

1 Investigação desenvolvida no âmbito do projecto «A História da Imprensa nos Açores - Séculos XIX e XX», apoiado pela Direcção Regional da Ciência, Tecnologia e Comunicações do Governo Regional dos Açores.

2 O Heroísmo, Angra do Heroísmo, 28 janeiro 1866.

3 Sobre o iberismo em Portugal veja-se, entre outros, Catroga, Fernando, «Nacionalismo e Ecumenismo. A Questão Ibérica na segunda metade do século XIX», en Cultura, História e Filosofia, 1985, vol. IV. Sobre o mesmo debate, mas nos Açores, veja-se CordEIRO, 
Nesse mesmo artigo em que louvava o governo português por ter guarnecido a fronteira com corpos militares, o jornal informava que se tinham refugiado em Portugal, entrados pela fronteira de Bragança, cerca de 450 militares espanhóis (400 praças e 49 oficiais), que teriam sido distribuídos por Lisboa e Peniche, «onde se lhes haviam preparado os necessários cómodos». O articulista considerava o general Prim «um dos homens mais liberais da nação vizinha e o mais abastado capitalista da Península» ${ }^{4}$. A partir da imprensa de Lisboa, os jornais açorianos transcreviam algumas das proclamações dos revoltosos exilados. Numa delas, Prim exaltava o modo como os militares sob o seu comando tinham sido recebidos em Portugal, quer ao nível oficial, quer pela população em geral, associando este carinho na recepção à comunhão dos ideais liberais da nação portuguesa por que, em Espanha, tinham lutado os exilados: «não me admira tal procedimento de um povo tão ilustrado e tão livre, mas não é por isso menos a minha gratidão» $»^{5}$. E o mesmo jornal de Angra do Heroísmo concluía:

«Como liberal que nos prezamos de ser, felicitamos o valente general Prim pela atitude enérgica e liberal que se propõe seguir na sua cruzada de regeneração para a sua pátria. Agradecemos as lisonjeiras frases que consagra ao nosso país, e só desejamos que esta trégua de infortúnio político, que ele e seus camaradas passam entre nós, a torne cada vez mais suportável a simpatia que a causa liberal de Espanha merece do povo português» ${ }^{6}$.

Assumindo, pois, uma atitude compreensiva e mesmo de apoio à causa liberal e democrática em Espanha, o jornal não deixa, porém, de destacar a existência de boatos que sugeriam que a ideia de união ibérica estaria subjacente às movimentações político-militares de Prim. Ao transcrever um artigo do jornal liberal de Lisboa, A Revolução de Setembro, o jornal terceirense afirma:

«Como se vê, nenhum dos gritos dos revoltosos é o da união ibérica como têm espalhado os homens que querem acarretar sobre aqueles bravos infelizes soldados os anátemas do povo português. É um grito de liberdade que levanta uma parte do exército, eco do país que há tanto tempo deseja tornar-se irmão do nosso pela identidade de leis» ${ }^{7}$.

De qualquer modo, e reflectindo no fracasso da revolução, o mesmo jornal da ilha Terceira concluiria que, por muito justos que fossem os objectivos, as revoltas militares não se coadunavam com os tempos que corriam. E, numa

Carlos, «O Iberismo e os Açores. Notas para uma investigação», Revista de História das Ideias, XII (1990).

4 Cf., O Heroísmo, Angra do Heroísmo, 28 janeiro 1866.

5 O Heroísmo, Angra do Heroísmo, 25 fevereiro 1866.

6 Ibidem.

7 Ibidem.

Pasado y Memoria. Revista de Historia Contemporánea, 9, 2010, pp 175-188 
posição já menos encomiástica do que a inicial, o editorialista avançava mesmo que, ao invés de conquistar a liberdade, a revolução a comprometera, visto que -«muito longe de ser generoso e tolerante com os vencidos ou suspeitos»- o governo espanhol agravara a repressão ${ }^{8}$. Numa apreciação profundamente negativa da situação em Espanha, considerava ainda que a liberdade em naquele país seria um mito. Nem todos os que se afirmavam liberais lhe rendiam «culto sincero», sendo até possível que, na eventualidade da sua vitória, os liberais também tivessem enveredado pela intolerância e a repressão sobre os vencidos: «todo o governo que se apoia na força militar para conservar o poder não está em melhores condições que qualquer partido que dela se socorra para derribálo» ${ }^{9}$.

Ainda assim, o articulista comunga da ideia iluminista do progresso da humanidade rumo à liberdade, apresentando uma visão optimista sobre o futuro de Espanha, que não podia ficar arredada da «lei geral do progresso da humanidade, nem recalcitrar às transformações que este decreta». O povo espanhol lutava e continuaria a lutar, mas por fim a Espanha havia de ser liberal, porque era «da ordem natural das coisas $»^{10}$.

A imprensa liberal «ordeira», digamos assim, acompanhou com o máximo interesse a evolução dos acontecimentos no país vizinho entre 1866 e 1868, comentando os acontecimentos numa perspectiva liberal conservadora. Com efeito, lamentava-se o atraso de Espanha quanto à estabilização e consolidação das instituições liberais, numa época em que os restantes países da Europa, à excepção da Grécia, já o haviam conseguido. Além disso, se seriam compreensíveis, aceitáveis ou mesmo necessárias «gloriosas» insurreições populares, pois, geralmente, resultavam de sentimentos generosos ou de uma «paixão» sustentada na opinião pública, as revoltas e sedições militares eram quase sempre, na opinião do articulista do jornal A Terceira, promovidas «pela desenfreada ambição pessoal de alguns generais» e constituíam uma verdadeira «chaga» que afligia as nações.

Esta perspectiva político-ideológica liberal moderada conduziria mesmo o autor a defender a legitimidade do governo em funções, destacando as suas medidas de tipo liberal: lei eleitoral mais liberal e democrática, eleições livres, reconhecimento do Reino de Itália. Os liberais avançados não tinham, porém, conferido ao governo tempo suficiente para governar nem sido cordatos de modo a prepararem a sua ascensão ao poder em futuras eleições. Em conclusão,

8 Ibidem, Angra do Heroísmo, 11 março 1866.

9 Ibidem.

10 Ibidem. 
e bem de acordo com a doutrina liberal, defendia-se para o "país vizinho» o primado da liberdade, da ordem e da tolerância ${ }^{11}$.

\section{O EXÍlio NOS AÇORES}

A imprensa do continente dava grande destaque à entrada destes cerca de 450 «revolucionários» em Portugal, comandados pelo general Prim. A imprensa açoriana, com os atrasos próprios das dificuldades de comunicações, ia fazendo eco destas notícias e do desenrolar dos acontecimentos.

Preocupações de natureza diplomática levaram o governo a expulsar Prim de Portugal, visto que um dos seus manifestos ou proclamações ${ }^{12}$ foi considerado como de incitamento à revolta contra as instituições de uma nação vizinha e amiga. Esta decisão levantou, aliás, várias vozes contrárias, sobretudo no parlamento. Com efeito, quer na Câmara dos Pares, quer na dos Deputados, o «convite» à saída do país do general Prim foi alvo de aceso debate, ainda que as vozes críticas relativamente à decisão do governo tivessem sido francamente minoritárias.

$\mathrm{Na}$ Câmara dos Pares, por exemplo, a censura ao governo partiu do marquês de Niza, que havia hospedado Juan Prim e demonstrava por ele amizade e admiração. Na sua perspectiva, a determinação do governo não tinha fundamentos sólidos, até porque, ao conceder asilo, e pelo facto de Prim ter recusado qualquer tipo de pensão ou subsídio, «não podia deixar de ser considerado um cidadão como qualquer outro, somente responsável perante as leis do país, as quais o manifesto por nenhum modo ofen[dia] $\aleph^{13}$.

Na sua resposta, o governo, através do presidente do Conselho, foi peremptório. Prim e os seus companheiros tinham recebido em Portugal provas da maior hospitalidade e simpatia. O próprio general tinha apresentara cumprimentos ao presidente do Conselho. Acontecera, porém, que Prim admitira a autoria do manifesto ou proclamação que incitava à revolta ou revolução num país vizinho e amigo. Em vez de aguardar que o governo espanhol, como seria expectável, apresentasse o protesto ao governo português, por aceitar tal atitude de um revolucionário que atentava contra as instituições de um país amigo, o governo português tomara a decisão de o «convidar» a deixar o país, cumprindo, neste aspecto, as suas obrigações definidas no direito internacional ${ }^{14}$.

11 A Terceira, Angra do Heroísmo, 27 janeiro 1866.

12 Transcrita em ibidem, Angra do Heroísmo, 31 março 1866.

13 Diário da Câmara dos Pares, Lisboa, n. ${ }^{\circ} 23,22$ fevereiro 1866, p. 566

14 Cf. Ibidem, p. 567. O debate prolongou-se ainda, pelo menos, por mais duas sessões da Câmara dos Pares. V. Diário da Câmara dos Pares, Lisboa, n. ${ }^{\circ} 24$ e 26, fevereiro 1866, respectivamente. 
Tendo o governo suspeitado da preparação de um movimento insurreccional dos exilados espanhóis em Portugal, mobilizou 24 mil reservistas do exército para fazer face a possíveis ameaças à ordem pública e decidiu transferir os espanhóis para os arquipélagos da Madeira, para onde foram deslocados os oficiais superiores $^{15}$, e dos Açores. Neste último arquipélago, o contingente foi dividido por duas ilhas -S. Miguel e Terceira- as duas ilhas mais populosas e com maiores capacidades económicas dos Açores. Não conseguimos alcançar o número exacto dos espanhóis «enviados» para as ilhas açorianas, mas, conjugando as informações de diversos jornais, a ilha de S. Miguel terá recebido entre 10 e 15 oficiais e a Terceira 254 «emigrados» (como sempre se lhes referia a imprensa) ${ }^{16}$, sendo certo que, em setembro de 1866, chegaram à Terceira mais sete exilados ${ }^{17}$.

O exílio de espanhóis nos Açores, por motivos políticos, não era, contudo, um facto inédito. Já em 1848 a ilha de Santa Maria havia «acolhido» cinquenta e dois deportados espanhóis. Uns eram militares que tinham estado envolvidos numa rebelião na província de Andaluzia, no contexto da Segunda Guerra Carlista. Outros tinham-se sublevado a bordo de um navio que viajava para Cuba. De um modo geral eram conotados com o partido Carlista. Tratando-se de uma ilha pequena e de parcos recursos aos mais diversos níveis, houve a necessidade de transferir alguns dos exilados para o hospital de Ponta Delgada (ilha de S. Miguel). Os que ficaram em Santa Maria provocaram desacatos, entregaram-se ao roubo, amedrontavam a população. Os desentendimentos entre os próprios exilados, em virtude de o oficial superior ter conduzido à justiça os prevaricadores, teve como desfecho um morto (o alferes Miguel Agaiada) e vários feridos.

Mediante o decurso dos acontecimentos e -segundo parece-em virtude dos protestos dos próprios exilados, que se queixavam do sofrimento de muitas privações na ilha de Santa Maria, o governo português acabou por ordenar o seu desterro para a ilha de S. Jorge. Porém, os que estavam em S. Miguel recusaram partir, alegando não serem assassinos, mas tão só presos políticos. Por consequência, seguiu apenas o grupo de Santa Maria que não só sofreu as vicissitudes de uma grande intempérie, como a recusa das autoridades jorgenses em os

15 Cf. O Açoriano Oriental, Ponta Delgada, 14 julho 1866.

16 Cf. A Terceira, Angra do Heroísmo, 14 julho 1866; Açoriano Oriental, Ponta Delgada, 21 julho 1866; Biblioteca Pública e Arquivo Regional de Ponta Delgada - Fundo do Governo Civil de Ponta Delgada, Livro 413, Ofício do Governador Civil de Ponta Delgada, 16 de julho de 1866. Pela consulta da correspondência do governador civil de Ponta Delgada, percebe-se que a estes exilados há a juntar outros, que chegaram às ilhas posteriormente. O próprio governador civil demonstra mesmo não ter a certeza absoluta do número de exilados na ilha de $\mathrm{S}$. Miguel.

17 A Terceira, Angra do Heroísmo, 22 setembro 1866. 
receber na ilha. Assim, estes 27 «emigrados espanhóis» acabaram também por arribar à ilha de $\mathrm{S}$. Miguel onde receberam alimentos e roupas. A maior dimensão, riqueza e densidade populacional desta ilha, comparativamente às outras, ajudou a esbater o impacte da presença dos expatriados estrangeiros. Não muito tempo depois, em outubro de 1848, por diligências do cônsul britânico, Thomas C. Hunt, e em resultado dos donativos angariados por particulares, lá partiram os deportados para Lisboa, deixando os agradecimentos públicos a todos quantos haviam concorrido para que pudessem regressar à sua pátria ${ }^{18}$.

Em 1866, o governo português não cometeu o mesmo erro, na medida em que enviou os exilados para as duas ilhas com maiores recursos e população (S. Miguel e Terceira). Os comandos militares foram responsabilizados pelo acolhimento e vigilância dos «emigrados», sendo certo que recebiam um subsídio pago pelo governo português ${ }^{19}$. Os militares foram instalados, em Ponta Delgada, no «Depósito de Emigrados», de que era comandante o alferes Luís Leopoldino Borges Bicudo ${ }^{20}$.

Os jornais das duas ilhas procuram criar um clima social propício a uma boa recepção aos «mártires da liberdade espanhola» por parte da população açoriana. Assim, foram imediatamente constituídas comissões de apoio que integraram membros importantes das elites sociais das duas ilhas e camaradas de armas, como aconteceu, por exemplo, com o comandante do Depósito de Emigrados Espanhóis em Ponta Delgada.

Ao verificarmos os nomes dos componentes das comissões de apoio, desde logo ressalta, na constituição das comissões masculinas, a presença da Maçonaria: dos dezoito participantes, conseguimos descobrir nove como integrantes de lojas maçónicas, ou seja, precisamente a metade ${ }^{21}$. Ora, esta circunstância será

18 As Escavações de Francisco Maria Supico, Escavações 32, Ponta Delgada, Instituto Cultural de Ponta Delgada, 1995, vol. I, pp. 62-63.

19 Cf., por exemplo, Biblioteca Pública e Arquivo Regional de Ponta Delgada - Fundo do Governo Civil de Ponta Delgada, Livro 488, Ofício do Governador Civil de Ponta Delgada, 16 de setembro de 1866.

20 Ibidem.

21 A primeira comissão era composta pelas seguintes senhoras: Condessa da Praia da Victória, Viscondessa de Bruges, Baronesa do Ramalho, D. Genoveva Leite de Carvalhal, D. Maria Augusta Zagallo Nogueira e D. Maria Serafina de Carvalhal Bettencourt. A segunda comissão foi formada pelo Conde da Praia da Victória, Visconde de Bruges, Barão do Ramalho, João de Carvalhal da Silveira, Dr. Rodrigo Zagallo Nogueira, Vital Bettencourt Vasconcelos e Teotónio S. Paim d'Ornelas Bruges (quase todos consortes das damas da primeira comissão). Finalmente a terceira, era constituída por Nicolau Anastácio de Bettencourt - Presidente, Barão de Noronha - Vice-presidente, Deão - Narciso António da Fonseca, Estulano Inácio Parreira, Joaquim António de Mendonça, António José Vieira Rodrigues Fartura, Tenente-Coronel José Maria de Bettencourt, Cândido Pacheco de 
bem indicativa, igualmente, da possibilidade de os «emigrados» terem também fortes ligações à Maçonaria, o que terá levado os mações açorianos a se empenharem no seu apoio, na linha da «fraternidade maçónica». Em S. Miguel, o alferes Luís Leopoldino Borges Bicudo, comandante do Depósito de Emigrados Espanhóis ${ }^{22}$, promoveu subscrições públicas a fim de conseguir meios para conceder melhores comodidades aos espanhóis. Também ele era mação, integrando a «Loja 17 de Março de 1866»"

Poucos dias após a sua chegada, os oficiais espanhóis foram «obsequiados» com um «lauto» jantar, numa quinta nos arredores de Ponta Delgada. Na altura dos brindes, Francisco Maria Supico, director do jornal A Persuasão e membro muito destacado da Maçonaria ${ }^{24}$, lançou um brinde aos «mártires da liberdade»:

«A liberdade é o único, e por isso mesmo imenso astro de resplandecente luz que ilumina os povos no seu contínuo lidar pelo progresso. Há-de ser ela que um dia fará desaparecer as fronteiras das nações e reunirá os habitantes do mundo inteiro em festim de fraternidade [...] Mas cada uma dessas conquistas custa aos povos provações enormes, leva aos altares das nações o tremendo sacrifício de muitas vítimas» ${ }^{25}$.

Mas, além dessa exaltação iluminista da liberdade como guia do progresso, dessa crença na futura fraternidade universal, dessa glorificação dos «mártires da liberdade», Francisco Maria Supico é extremamente radical na crítica à monarquia espanhola, destacando a revolução como «a voz de Deus anunciando aos déspotas a sua hora extrema» a que, posteriormente, a nação espanhola ficaria a dever «a emancipação dos seus filhos [...] de jugo tão odioso». O sangue derramado em defesa da liberdade e do «combate das ideias» seria o «embrião das tempestades» que, mais tarde, sepultariam «nos seus próprios tronos [os] ídolos de barro adornados com ceptros de ignomínia».

Por fim, um apelo à tolerância e à generosidade dos que seguiam convictos a «religião do progresso» e que, sem dúvida, venceriam a tirania: teriam que perdoar os seus «algozes» e serem «generosos como a liberdade» ${ }^{26}$. Trata-se, se não erramos muito, de um discurso que qualquer republicano da época subscreveria,

Melo, José Maria Parreira, Júlio Gomes Carvalho Ferreira - Tesoureiro, José Maria Seuve de Menezes - Secretário. O Melrinho, Ponta Delgada, 1 agosto 1866. Cf. Lopes, António, A Maçonaria Portuguesa e os Açores 1792-1935, Lisboa, Ensaius, 2008, pp. 343-354.

22 Assim era designado pelo governador civil. Os exilados foram instalados em três casas devidamente apetrechadas com base nos donativos arrecadados pelo comandante do Depósito de Emigrados Espanhóis.

23 Cf. LOPES, António, ob. cit., pp. 315-316.

24 Cf. ibidem, p. 316.

25 A Persuasão, Ponta Delgada, 1 agosto 1866.

26 A Persuasão, Ponta Delgada, 1 agosto 1866.

Pasado y Memoria. Revista de Historia Contemporánea, 9, 2010, pp 175-188 
mas que fora proferido por um monárquico do Partido Regenerador português ${ }^{27}$.

Num outro editorial, o jornal A Persuasão, como aconteceu com diversos outros $^{28}$, testemunhava a boa recepção de que os «emigrados» tinham sido alvo na sociedade açoriana, que dera mostras de grande hospitalidade. Afirmava-se mesmo que a «solicitude e desvelo» com que os açorianos tinham dado o «abraço fraterno» aos «mártires da liberdade» passaria a constituir um dos muitos títulos honoríficos de que se podiam orgulhar os Açores:

«O exílio em terras livres não é expiação nem arrependimento, é o abraço fraterno de irmãos pela mesma fé e crença no futuro da humanidade, é o afervorar das ideias retemperando os corações para novas lutas, para o apostolado nobre a que incitam as palmas do triunfo ${ }^{29}$.

Como é natural, os exilados também se serviam da boa vontade da imprensa para publicarem textos de vivo reconhecimento pelo modo afectuoso como foram recebidos e pelos apoios que lhes tinham sido concedidos. O comandante das praças de pré colocadas na ilha Terceira dirigiu, através da imprensa, um agradecimento à comissão de apoio que oferecera a cada um dos militares um par de sapatos e um par de calças. Manoel Marcos associava, aliás, a generosidade no acolhimento à comunhão dos ideais liberais, numa ilha que, como lembrava, fora «o primeiro baluarte da liberdade portuguesa $»^{30}$. Em S. Miguel, o oficial espanhol mais graduado designava os habitantes da ilha como «honestos e hospitaleiros», que haviam acolhido os exilados com a maior simpatia, quer pela sua condição de exilados, quer pela causa por que tinham lutado. Neste mesmo agradecimento público, dava a conhecer o facto de os oficiais serem recebidos em casa de famílias locais ${ }^{31}$.

Mesmo tendo em consideração os apoios de que foram alvo e os subsídios oficiais concedidos, as condições de vida desses exilados civis -o governador civil refere-se a «emigrados por opiniões políticas» ${ }^{32}$ - e militares não devem ter sido fáceis. É assim que iremos encontrar um sargento a anunciar, na imprensa da ilha Terceira, que procurava trabalho e é também sintoma desse mal-estar a

27 Cf. «Francisco Maria Supico republicano na política regeneradora -suas relações com escritores e políticos- por correspondência inétita», Revista Micaelense, Ponta Delgada, 1. ${ }^{\circ}$ ano, 1919.

28 V., por exemplo, O Açoriano Oriental, Ponta Delgada, 21 julho 1866; Angra do Heroísmo, 11 agosto 1866.

29 A Persuasão, Ponta Delgada, 8 agosto 1866.

30 A Terceira, Angra do Heroísmo, 17 novembro 1866.

31 A Persuasão, Ponta Delgada, 14 novembro 1866.

32 Biblioteca Pública e Arquivo Regional de Ponta Delgada - Fundo do Governo Civil de Ponta Delgada, Livro 488, Ofício do Governador Civil de Ponta Delgada, 11 de junho de 1868 . 
apresentação de uma queixa dos militares que se encontravam naquela ilha contra o respectivo comandante, Manoel Marco, por considerarem que geria mal os fundos colectivos (deduz-se que dos subsídios oficiais e das ofertas da sociedade local). Investigado o caso, nada constou em desabono do responsável ${ }^{33}$.

Refira-se, entretanto, que houve mobilidade dos «emigrados», pelo menos dos civis, nos Açores. De facto, há notícias de espanhóis exilados em diversas ilhas do Grupo Central do arquipélago ${ }^{34}$. De S. Miguel, a pedido dos próprios e com autorização do governo, deslocam-se para a ilha do Faial, em junho de 1868, quinze emigrados «por opiniões políticas» ${ }^{35}$ e da Terceira seguiram também para o Faial outros dez ${ }^{36}$. Não conseguimos acesso aos requerimentos para podermos ficar com uma ideia mais clara sobre os fundamentos dos pedidos de transferência, sendo certo que a ilha de S. Miguel, como a maior, mais populosa e desenvolvida economicamente, seria, em princípio, a que melhores condições ofereceria para a instalação e manutenção dos exilados. Assim, não conseguimos descortinar as razões para estes pedidos de deslocação inter-insular, excepto a possibilidade da existência de laços de amizade e solidariedade entre os que se encontravam no Faial e os que para lá pediam transferência. É também possível que os «emigrados» no Faial, na sua correspondência com os de Ponta Delgada, tenham informado que as condições de acolhimento e o ambiente social que os rodeava eram positivos.

Mas nem tudo correu bem durante a estadia dos espanhóis nos Açores. $\mathrm{Na}$ ilha Terceira, onde tinha sido colocado o maior contingente, verificaram-se roubos numa freguesia rural, pelo que a autoridade local determinou a proibição da saída dos exilados da cidade de Angra do Heroísmo ${ }^{37}$. Outros excessos, ainda que, pelas notícias dos jornais, não pareçam ter sido de gravidade, foram punidos com o afastamento de alguns militares da ilha Terceira para a do Faial ${ }^{38}$.

Mais grave e complexo foi o resultado da publicação, num jornal de Ponta Delgada, de um conjunto de artigos, em jeito de folhetim e em termos romanceados, com nomes fictícios, mas que não deixavam dúvidas sobre o objectivo que visavam: a ridicularização e descredibilização dos espanhóis exilados na ilha

33 Cf. A Terceira, Angra do Heroísmo, 27 abril 1867.

34 Veja-se, por exemplo, O Açoriano Oriental, Ponta Delgada, 16 fevereiro 1867; Angra do Heroísmo, 31 outubro 1868.

35 Biblioteca Pública e Arquivo Regional de Ponta Delgada - Fundo do Governo Civil de Ponta Delgada, Livro 488, Ofícios do Governador Civil de Ponta Delgada, 9, 11 e 25 de junho de 1868 .

36 O Atlântico, Horta, 31 janeiro 1867.

37 Veja-se. O Clarim Terceirense, Angra do Heroísmo, 26 dezembro 1866.

38 Veja-se A Persuasão, Ponta Delgada, 6 fevereiro 1867. 
de S. Miguel e também o ataque à honra e hombridade de uma família local ${ }^{39}$. Este conjunto de artigos foi ainda agravado pelo editorial assinado pelo redactor em que se justificava a interrupção da saída do folhetim «Um conto de minha avó». O facto é que o redactor desafiava directamente os heróis (em itálico no texto), que «tão miseravelmente» se tinham fixado na ilha de S. Miguel, a virem cobrar desagravo junto do redactor, caso se considerassem ofendidos. E termina o editorial:

«Saibam que não lhe desejamos mal algum nem agravar a sua posição; mas se continuarem a insultar quem de nem deles se lembra, reclamaremos então providências sérias contra os infames que vieram trazer o desgosto e, porventura, a desonra ao seio de famílias honestas, cuspindo assim nas mãos liberais dos seus benfeitores de ontem $»^{40}$.

Ora, mais do que o folhetim, que era já suficientemente ofensivo, quer para os espanhóis ou algum em especial e para uma determinada família da ilha, este editorial é ainda mais grave, ao envolver na situação todos os exilados e as circunstâncias da sua vinda, considerando-os «miseráveis» e ingratos relativamente a quem os tinha recebido com «mãos liberais».

Em público, numa sessão do Teatro local, o espanhol visado foi procurar o redactor, para lhe cobrar desagravo, chegando à agressão física. A imprensa criticou os acontecimentos, geralmente os dois contendores, ainda que alguns artigos fossem mais favoráveis ao espanhol e outros ao redactor ${ }^{41}$. Na sequência deste acontecimento, e segundo correspondência do governador civil, os oficiais espanhóis chegaram a ser provocados e insultados na via pública ${ }^{42}$.

Não conseguimos, como é natural, ficar com uma ideia clara do que verdadeiramente aconteceu. Tendo mesmo a hospitalidade dos habitantes de S. Miguel sido considerada exemplar, o certo também é que as relações sociais que os exilados foram estabelecendo não deixariam, decerto, de provocar a circulação de rumores sobre questões de ordem afectiva ou comportamental, o que bem se compreende se se tiver em consideração que se tratava de uma sociedade pequena e de índole conservadora.

39 Veja-se o Campeão Liberal, Ponta Delgada, 9, 16 e 23 novembro.

40 Campeão Liberal, Ponta Delgada, 30 novembro 1866.

41 Veja-se O Açoriano Oriental, Ponta Delgada, 22 dezembro 1866; A Persuasão, 5, 12, 14 , 19 dezembro 1866 e 2 janeiro 1867.

42 Biblioteca Pública e Arquivo Regional de Ponta Delgada - Fundo do Governo Civil de Ponta Delgada, Livro 27, Ofício do Governador Civil de Ponta Delgada, 13 de dezembro de 1866. Neste ofício, o governador civil recomenda à autoridade policial a necessidade de investigar os casos, a fim de serem respeitadas as leis e os «deveres de hospitalidade». 


\section{$\mathrm{O} \ll$ REGRESSO A CASA»}

Em maio de 1867, chega aos Açores a notícia de que o governo espanhol concedera amnistia aos soldados e cabos espanhóis envolvidos nos acontecimentos revolucionários do ano anterior ${ }^{43}$. $O$ governo português enviou um barco às ilhas para transportar para Cádis os exilados que a aceitassem. Mesmo antes da chegada da notícia, o comandante dos exilados que se encontravam na Terceira recusava uma hipotética amnistia, considerando que seria uma desonra ${ }^{44}$, no que é seguido por um sargento que publica uma declaração na imprensa local, manifestando o seu desprezo pela ideia ${ }^{45}$.

De facto, só uma parte dos «emigrados» aceitou a amnistia e seguiu num navio português rumo a Cádis. No caso da ilha Terceira, por exemplo, das cerca de duas centenas e meia de exilados, embarcaram somente $182^{46}$. Os restantes ficaram a aguardar o decorrer dos acontecimentos em Espanha.

A Gloriosa Revolução de setembro de 1868 iria pôr termo ao exílio. Com efeito, confirmada a vitória liberal, os exilados que se encontravam ainda nos Açores seguiram rumo a Lisboa em finais de outubro e inícios de novembro de 1868. Antes da partida, os que se encontravam na ilha de S. Miguel promoveram uma manifestação pública que percorreu as ruas da cidade de Ponta Delgada, saudando as autoridades e particulares que lhes haviam tornado o exílio, que excedeu dois anos, mais suportável.

«Os espanhóis, alguns, com tocatas na noite da véspera do seu embarque, percorreram as residências das autoridades e de outros cavalheiros a quem deviam, talvez, finezas, dando muitos vivas com grande entusiasmo, não havendo nada que motivasse qualquer arrufo se atendermos ao muito povo que os acompanhava» ${ }^{47}$.

Esta permanência de mais de dois anos nas ilhas deixaria também importantes laços afectivos, de tal modo que alguns dos exilados não regressaram à pátria por terem «criado laços familiares» na ilha Terceira ${ }^{48}$.

43 Cf. A Terceira, Angra do Heroísmo, 25 maio 1867.

44 O Angrense, Angra do Heroísmo, 22 novembro 1866.

45 Ibidem, 22 novembro 1866.

46 Veja-se A Persuasão, Ponta Delgada, 3 julho 1867.

47 O Açoriano Oriental, Ponta Delgada, 31 outubro 1868.

48 O Micaelense, Ponta Delgada, 30 outubro 1868. 


\section{EM CONCLUSÃO}

Ainda que o exílio de espanhóis nas ilhas dos Açores, por motivos políticos ou político-militares, não tivesse sido, como referimos, caso inédito, o certo é que nesses anos de 1866-1868 a hospitalidade de que foram alvo ultrapassou a exclusiva manifestação de sentimentos humanitários para se situar também no plano ideológico. A leitura da imprensa é bem demonstrativa disso mesmo e quando os espanhóis eram criticados, como aconteceu com o episódio do folhetim, havia logo um coro de protestos de grande parte da imprensa liberal.

Evidentemente que nem tudo terá corrido sempre bem. Mas, se verificarmos que mais de 250 exilados se encontravam concentrados numa cidade, como Angra do Heroísmo, que não atingia os 12 mil habitantes, podemos então ficar com uma noção mais correcta do impacte desta «leva» de espanhóis, militares e civis, na sociedade local. Por isso mesmo se julga importante destacar o facto de, pelo menos tendo em conta a leitura da imprensa, não se terem verificado conflitos sociais ou alterações da ordem pública de monta.

Por outro lado, as autoridades civis e militares e elementos das elites sociais procuraram lidar com «o problema» de um modo positivo, a fim de criarem um bom ambiente para a aceitação pública dos «mártires da liberdade», que, em terras distantes e com um pequeno subsídio, teriam que «sobreviver» o melhor possível. Puderam contar com a solidariedade da população, que também vivia com graves dificuldades económicas. Disso são prova os donativos entregues aos exilados.

Faltam-nos, infelizmente, muitos elementos que nos podiam ajudar a compreender o quotidiano dos espanhóis nos Açores, mas também o modo como estavam organizados internamente e as suas relações com as autoridades civis e militares.

Ora, a própria correspondência oficial é muito lacónica, não permitindo tirar grandes conclusões. A ideia geral com que se fica é a de que, apesar de tudo, os deveres de hospitalidade foram, dentro das possibilidades, cumpridos pelas comunidades onde se instalaram os exilados. 